\title{
Digital engagement methods for earthquake and fire preparedness: a review
}

\author{
Enrica Verrucci ${ }^{1}$ - Gabriela Perez-Fuentes ${ }^{2}$ - Tiziana Rossetto ${ }^{1}$ • \\ Luke Bisby $^{3} \cdot$ Muki Haklay $^{4}$ - David Rush ${ }^{3}$ - Patrick Rickles ${ }^{4}$. \\ Gretchen Fagg $^{4} \cdot$ Helene Joffe ${ }^{2}$
}

Received: 3 November 2015/ Accepted: 19 May 2016/Published online: 1 June 2016

(C) The Author(s) 2016. This article is published with open access at Springerlink.com

\begin{abstract}
Natural or human-made hazards may occur at any time. Although one might assume that individuals plan in advance for such potentially damaging events, the existing literature indicates that most communities remain inadequately prepared. In the past, research in this area has focused on identifying the most effective ways to communicate risk and elicit preparedness by means of public hazard education campaigns and risk communication programmes. Today, web- and mobile-based technologies are offering new and far-reaching means to inform communities on how to prepare for or cope with extreme events, thus significantly contributing to community preparedness. Nonetheless, their practical efficacy in encouraging proactive hazard preparedness behaviours is not yet proven. Building on behaviour change interventions in the health field and looking in particular at earthquakes and fire hazards, the challenging RISK team has reviewed the currently active websites, Web, and mobile applications that provide information about earthquake and home fire preparedness. The review investigates the type of information provided, the modality of delivery, and the presence of behaviour change techniques in their design. The study proves that most of the digital resources focus on a single hazard and fail to provide context-sensitive information that targets specific groups of users. Furthermore, behaviour change techniques are rarely implemented in the design of these applications and their efficacy is rarely systematically evaluated. Recommendations for improving the design of Web- and mobile-based technologies are made so as to increase their effectiveness and uptake for a multi-hazard approach to earthquake and home fire preparedness.
\end{abstract}

Enrica Verrucci

e.verrucci@ucl.ac.uk

1 Department of Civil, Environmental and Geomatic Engineering, University College London, Gower Street, London WC1E 6BT, UK

2 Division of Psychology and Language Sciences, University College London, London, UK

3 BRE Centre for Fire Safety Engineering, University of Edinburgh, Edinburgh, UK

4 Geographic Information Science, University College London, London, UK 
Keywords Earthquake preparedness - Home fire preparedness - Digital behaviour change Preparedness mobile apps

\section{Introduction}

It is clearly in an individual's best interest to take actions to reduce their vulnerability before a hazardous natural or human-made event occurs. However, the existing literature shows that most communities fail to take adequate steps to mitigate against the effects of such events, even in areas where disasters occur with relatively high frequency (Joffe et al. 2013; Solberg et al. 2010; Karanci et al. 2005; Rüstemli and Karanci 1999).

Even though many people remain excluded from access to global communication networks, particularly those in potentially vulnerable groups in society and/or in specific geographic regions, the Internet is clearly a key medium for the dissemination of public information (Johnson 1998). The contemporary worldwide diffusion of both Web-based and mobile technologies is unprecedented and on the rise. Estimates from the International Telecommunication Union (ITU) suggest that Web technology uptake is still experiencing exponential growth, with almost three billion people using the internet. This corresponds to a global penetration rate of $40.4 \%$ at the end of 2014. Data on the diffusion rate of mobile technologies are also striking, with approximately $48 \%$ penetration globally: $63 \%$ in developed countries, $45 \%$ in developing countries, and $30 \%$ in the least developed countries (ITU 2014).

Undoubtedly, the global diffusion of Web-based and mobile communication technologies continues to affect the dynamics of the communication of hazards and disasters (Briones et al. 2011; American Red Cross 2010; United Nations-APCICT/ESCAP 2009). As a result, a growing number of institutions working in the hazard/disaster management field are attempting to utilise the power of the internet by developing websites and mobile applications aimed at communicating information concerning disaster preparedness to the general public.

Nonetheless, the provision and availability of preparedness information are not sufficient elements for prompting behaviour change in community preparedness (Coyle and Meier 2009; Norris et al. 2008; Ballantyne et al. 2000; Lindell and Whitney 2000; Duval and Mulilis 1999). Simple and culturally relevant preparedness guidelines, if widely and appropriately distributed by means of new information and communication technologies (ICT), may encourage more proactive behaviours towards hazard mitigation and preparedness. Yet, to date, no evaluated studies demonstrate unequivocal examples of behavioural changes related to web-based and mobile communication technologies in the field of hazard preparedness. In fact, some authors remain sceptical concerning the benefits of the use of ICT, as well as of social media, in disaster risk reduction and response (Giroux et al. 2013; Lindsay 2011).

Several aspects must be considered to evaluate if such novel means of communication of preparedness information can effectively support the creation and maintenance of proactive preparedness behaviours. First of all, the way information is perceived and interpreted de facto determines whether or not action will follow (Paton et al. 2010b). The availability of information on the Web or from mobile applications increases the number of people that receive the information but does not necessarily affect their perception (Jaeger et al. 2011; McGowan and Sauter; 2005). Hence, understanding how perception influences 
responses is crucial for the design of effective methods for preparedness information's communication and distribution.

Disaster preparedness is influenced by a wide range of factors (Paton and Johnston 2015; Johnston et al. 2013; Paton et al. 2005, 2010a; Tierney et al. 2001). Such factors include socio-demographic characteristics (e.g. homeownership, income, education, marital status, disability) but also individual social contexts and experiences (e.g. number of years in the neighbourhood, previous disaster experience, level of participation in community activities). Furthermore, issues such as trust, beliefs, and perceptions about personal and community efficacy influence the ways in which information is consumed and used (Paton et al. 2008; Paton 2007; Devine-Wright and Devine-Wright 2004). Anxiety levels also play a major role in disaster preparedness (Joffe et al. 2013).

In the literature, preparedness activities are classified in distinctive functional categories: structural preparedness, planning, survival, community, and community agency (Paton et al. 2015). The first functional category refers to tangible home-hazard mitigation measures aimed at limiting the extent of damage to the structure. The planning category embraces the aspects of preparedness associated with having a family preparedness plan and well as the abilities and resources to implement such plan. The survival functional category encompasses all actions aimed at increasing the chance of withstanding the immediate aftermath of a disaster without loss of life. These include having an emergency kit and stockpiling essentials. The last two functional categories refer explicitly to the propensity of a single individual to engage with the community, in passive (i.e. getting involved as a recipient of existing training activities) or active ways (i.e. preparing new community preparedness plans).

The work of Russell et al. (1995) and Lindell et al. (2009) confirms that people tend to be better prepared in the survival and planning categories, but are generally less prepared in the structural and community-based preparedness activities. This finding prevails despite the evidence that greater community involvement correlates with an increased sense of agency in relation to preparedness (Paton 2006).

Since people's perceptions so greatly influence the type of actions implemented, information on hazards needs to be suitably tailored and adequately delivered in order to be effective. It also important to consider that people may be adequately prepared for some of the preparedness functions but lack resources (such as time and money), ability, motivation, and/or status (i.e. homeownership) to implement the others. Hence, the content of preparedness information and the modality of delivery should be focused on achieving a more comprehensive evidenced-based approach to preparedness. Furthermore, societal and individual preparedness may evolve and develop based on individual and community experiences. Some studies argue that the number of earthquakes experienced is an antecedent of preparedness (Tierney et al. 2001; Russell et al. 1995), though others (e.g. Johnston et al. 1999) show that people who experience past natural disasters show lower preparedness levels than people unaffected. Hence, Web-based and mobiles applications may need to take heed of the past experiences of their users in the information provided.

This paper reviews strengths and weaknesses of the currently available and active Weband mobile-based resources that provide information for earthquake and home fire preparedness. It does so against the backdrop of gaps in knowledge in the evaluation of the efficacy of ICT for behaviour change in the disaster risk reduction and response field and in line with the aspects outlined above. The review is structured around two main research enquiries. The first concerns an in-depth analysis of the type and content of the information delivered to advise the public about home fire, earthquake, and fire-earthquake mitigation and preparedness. Indeed, whilst earthquakes and fires are frequently associated-typically 
with significant fires or urban conflagrations following major earthquakes-the combination of these hazards has received scant attention from researchers in the field of preparedness. This is especially important in terms of multi-hazard community preparedness, which is arguably an area that could make a significant contribution to public safety. The second aspect of the enquiry investigates how behaviour change techniques, such as reminders and rewards, have been included in the design of Web- and mobile-based applications. These have proven effective in the health field.

The findings of the two enquiries are presented jointly and organised based on the following five criteria: (a) Delivery of multi-hazard earthquake-fire preparedness information; (b) Competence of the information provider; (c) Level of interaction between host/moderator and the general public and between the users, (d) Delivery of actionable (i.e. with practical description of the task to perform) and comprehensive information (i.e. covering all of the functional categories) and (e) Cultural relevance to specific context/group. On the basis of the findings of the use of Web- and mobile-based interventions for behaviour change, two other evaluation criteria were added. These include the implementation of ( $\mathrm{f}$ ) Reminders, Positive Reinforcement, Rewards and (g) means of Evaluating habit formation in preparedness. An evaluation matrix is used to summarise the findings of the review.

\section{Lessons learned in using information and communication technologies for behaviour change in the health field}

Web-based and mobile-based applications have had some success in eliciting behaviour change in the health field. Mobile interventions have been widely used for treatment adherence and to promote healthy behaviours (Wayne and Ritvo 2014; Khadjesari et al. 2011; Krishna et al. 2009; Brendryen et al. 2008). A systematic review of healthcare interventions via mobile phones undertaken by Krishna et al. (2009) showed that $80 \%$ of the participants reported changes in behaviour after receiving information via text message or voicemail. Similarly, Free et al. (2013) conducted a systematic review and concluded that mobile-based interventions could be a powerful tool to provide individual support and promote adherence to treatment. Other evaluations of behaviour change interventions delivered via the Internet have shown that on average interventions have a statistically small but significant effect on health-related behaviours, with an increased success rate with a more extensive use of theoretically driven interventions (Michie et al. 2008). Finally, it was also shown that the effectiveness of internet-based interventions was enhanced by the use of additional methods of communicating with participants, especially the use of short message services (SMS), or text messages (Webb et al. 2010).

The above research evaluates the successes and pitfalls of the application of web-based and mobile-based interventions to foster behaviour change, determining that effective interventions share some common design characteristics (e.g. targeting specific groups, mobile apps reminders). The literature also highlights the need to establish ways to perform ongoing monitoring of the uptake and use of such technologies. Once behaviours have changed, these must be continuously evaluated to monitor long-term changes. The existing literature shows that habits are formed by repeating the same behaviour in the same context over a period of approximately 12 weeks (Lally et al. 2010). In addition, it has been shown that reminders improve adherence and behaviour maintenance, but that they hinder habit formation; arguing that people will rely on the reminder rather than their own motivation to 
follow up on a new behaviour (Michie et al. 2008). Rewards (e.g. financial rewards, lottery entries), on the other hand, have been found to be more effective as they act as positive reinforcements and encourage people to continue repeating their new behaviours, thus increasing the strength of their habits (Hunter et al. 2013; Kimmel et al. 2012; Haisley et al.,2012; Milkman et al. 2011; Michie, et al. 2008). As a result, new apps targeted for behaviour change are being carefully designed to include multiple theory-based behaviour change techniques - to start the behaviour change process-as well as consistent monitoring to facilitate habit formation (Bailey et al. 2015a, b).

\section{Current use and limitations of information and communication technologies in the disaster risk reduction and response field}

In the field of disaster risk reduction and response, IC technologies have traditionally received the greatest research attention in the relatively narrow field of post-disaster response (Reddick 2011; Shklovski et al. 2010) and in the nascent field of early warning dissemination (United Nations-ESCAP 2009). In disaster response, such technologies were first used to support emergency managers during response operations. More recently, Weband mobile-based technologies have turned towards applications that help communities stay connected and informed (Shklovski et al. 2010; Palen et al. 2007).

Websites and mobile apps are now being used to gather and disseminate information about the occurrence, intensity, and areas affected by natural and human-made hazards. Some websites and mobile applications also provide guidance on how to prepare for or cope with extreme events. In this context, Web and mobile-based technologies are primarily used as hubs of information distributed to, as well as created by, a community of users. They depend heavily on social media for information exchange (Palen et al. 2007).

Such characteristics suggest that Web-based and mobile technology can effectively facilitate information distribution and the creation of peer-to-peer communication networks within communities-key elements of preparedness (Norris et al. 2008). However, there is no evidence that the content of the information distributed and the modality of distribution in the field of disaster management and response can effectively fulfil the purpose of eliciting behaviour change in preparedness.

As mentioned, the literature on the psychology of risk details how the provision of information per se is not inherently associated with its reception and application (Paton et al. 2008; Paton and Johnston 2001; McKenzie-Mohr 2000). There is a common assumption that it is a lack of information that leads to a lack of action to prepare for hazards. Those studies that operate with this assumption have been termed 'information deficit model' studies since they wrongly hypothesise that provision of more and/or better information will solve the lack of preparedness problem (Sturgis and Allum 2001; Eden 1996; Evans and Durant 1995; Bauer et al. 1994; Smith 1993). Another important aspect to be considered is how natural hazard preparedness is perceived in relation to the other risks of everyday life. People manifest a strong inclination to discount the importance of low frequency hazards in relation to more pressing, frequent perils (Eiser et al. 2012). Nowadays, scientists in the field of disaster preparedness agree that it is a combination of cognitive, emotional, and sociocultural factors that affect preparedness.

In addition to addressing cognitive, emotional and sociocultural factors affecting preparedness, the modality in which information is provided to the users to help them stay connected and informed after a disaster may not encourage proactive behaviour change in 
earthquake-fire preparedness. The observation invites a detailed analysis of the content and design of the currently available Web and mobile resources that provide such information.

\section{Selection criteria for earthquake and fire safety preparedness Web and mobile resources}

The collection of websites and/or Web- and mobile-based applications containing earthquake and fire hazard preparedness information was compiled via Web-browsing. A first search was undertaken in September 2013, and then updated throughout 2014 and early 2015 when new applications were added. The full list of the reviewed web- and mobilebased resources is available at http://www.ucl.ac.uk/challenging-risk/websites-and-apps.

The process of selecting keywords and using readily available search engines can be considered as a version of the 'cognitive walkthrough' procedure that is part of usability engineering (Rogers et al. 2011). In cognitive walkthrough, the evaluator creates a scenario of application use, along with a description of the users, in terms of background knowledge, and then checks to see whether the application is effective for such an imagined user by trying to use ICT in the expected manner. In order to replicate the actions that lay people would perform on the internet or on their smartphones when looking for Webdelivered preparedness information, search keywords included not only the standard disaster preparedness terminology (e.g. "earthquake/home fire preparedness", "preparation for disasters", "disaster prevention", "preparedness programs") but also common search phrases, such as "how do I prepare for an earthquake?"

For the mobile applications search, a preliminary list of applications was compiled from the marketplace of each operating system (i.e. Blackberry World, iTunes, Google Play, and Amazon App Store). Browser-supported applications and widgets were reviewed separately by browsing in the add-ons library of each browser. Keywords used included "earthquake", "home fire", "preparedness" and their combinations (e.g. "earthquake preparedness", "prepare for earthquakes"). The results of this preliminary phase were supplemented with a snowballing technique using fast-search engines (e.g. SimilarWeb, SimilarSites and SimilarPages for websites; Xyo Beta for applications).

All of the resources selected were screened for their relevance to the review. The evaluation criteria included: (1) the specific hazards of interest, (2) information about the hosting organisation/provider, and (3) the level of interaction between websites, host/moderator, and the general public.

Based on the type of provider, websites were separated into two categories: Primary if the information was provided by public institutions and other organisations officially working in disaster risk reduction and management, or Secondary if the provider of information was unofficial (e.g. bloggers). The review does not include "one-off" sources (e.g. blogs and posts about preparedness distributed after a disaster has occurred). The level of interaction for information distribution has been categorised as active if users are able to generate and add content to the website, or passive if the website is simply intended to deliver information. For the applications, collected data include (1) hosting/operating systems (Android, Apple, BlackBerry for mobile apps; Mac, Windows, Linux, Chrome for web-apps; Firefox, Chrome for add-ons to popular web-browsers) and (2) the type of information disseminated (e.g. near-real-time feeds of events, real-time alerts, and preparedness guidelines). 
Efforts have been made to provide additional data regarding the total number of people contributing/using these applications. Statistical information on Web traffic of each website (using the fast-search engines) and the number of downloads of each application (using Xyo Beta) were investigated. However, such data have been found to be unsatisfactory in providing conclusive evidence of the number of active users. In fact, website traffic information only refers to the main domain of the page and information on the users of preparedness pages is disaggregated. By the same token, the number of downloads, whilst offering an indication of the popularity of the apps, does not provide any conclusive evidence as to the number of active users.

In terms of analysis of the content of the applications, the review has focused on resources providing information about earthquake and/or home fire preparedness. According to the United Nations Office for Disaster Risk Reduction (UNISDR), preparedness is defined as "The knowledge and capacities developed by governments, professional response and recovery organizations, communities, and individuals to effectively anticipate, respond to, and recover from, the impacts of likely, imminent or current hazard events or conditions" (UNISDR 2009:21). This widely accepted definition of preparedness highlights the activities that are recognised in the field as part of a proactive preparatory behaviour. The definition encompasses all activities and behaviours that either mitigate immediate risks of human and economic loss due to infrastructure or environmental damage, or prepare for and increase chances of survival, efficient response, and recovery in the aftermath of a destabilising major hazard event, natural or otherwise (Turner et al. 1986; Mulilis and Lippa 1990; Lindell and Perry 2000; Spittal et al. 2006; Joffe et al. 2013). Such activities include, for instance, stockpiling of equipment/supplies, the development of coordination and emergency plans, evacuation and public information, and related training and field exercises, all of which must be supported by formal institutional, legal, and budgetary capacities (UNISDR 2009). As such the definition reflects, at least in part, the functional aspects of preparedness highlighted in Russell et al. (1995)'s and Lindell et al. (2009)'s work, although more emphasis should be given to the community aspects of preparedness that are included as part of the following review.

\section{Results and evaluation of the findings}

As of 5 March 2015, the general Web search included 85 active websites, whilst the applications' marketplaces search returned 159 mobile apps. Based on the methods usedwhether by popularity or familiarity of developers with the technologies-websites, Android, and Apple mobile applications represent the majority of resources analysed in the study $(82 \%)$.

\section{(a) Delivery of multi-hazard earthquake-fire preparedness information}

Despite the relatively greater frequency of fires, it was observed that the quantity and level of detail of home fire preparedness information available on Web- and mobile-based resources are very limited compared to earthquake preparedness resources. Indeed, the great majority of the websites (76 over a total of 85) only provide information about earthquake preparedness, 21 websites address both earthquake and post-earthquake home fire but only nine websites focus specifically on home fires. For mobile applications it was also observed that, with the exception of Emergency AUS for Android (which indicates the location of reported home fires), none of the reviewed apps deals specifically with home 
fire hazard preparedness. This may suggest that fire preparedness has not pervaded public awareness in the way that earthquake preparedness has; possibly because people may have low awareness of fire hazards and may not-for whatever reason-feel the need to take preventative actions against fires, or may have become desensitised to fire risks due to fire alarm system tests or drills (Meacham 1999). The few available resources that do address both earthquakes and fires send out the message that both require specific preparedness actions, particularly as a fire may result from an earthquake, and planning for the latter may not adequately address the former.

\section{(b) Competence of the information provider}

It was found that Web-delivered preparedness information is mainly supplied by primary providers $(80 \%$ of all the websites analysed). These are made up of governmental institutions (72\%) and NGOs (7\%), as well as educational bodies (15\%) with mandates on disaster risk and management. Other primary providers include blogs about preparedness $(3 \%)$, and private/public partnerships (3\%), such as the Earthquake Alliance Organization.

As far as mobile applications are concerned, it was noted that these are designed by both primary and secondary providers but predominantly work as "on-the-go" systems for dissemination of live earthquake data feeds coming from webpages of earthquake research institutions (e.g. the US Geological Survey, European Mediterranean Seismological Centre, Natural Resources Canada, British Geological Survey) or governmental agencies. This observation reinforces the initial hypothesis that primary providers play a crucial role in the delivery of earthquake and fire preparedness information.

(c) Level of interaction between host/moderator and the general public and between the users

With regard to interactivity and the possibility for users to contribute with preparedness information that might help others, it was found that the modality of distribution of preparedness information typically remains unidirectional, with governmental agencies and the scientific community acting as the main information providers. All the reviewed websites link to social networks (e.g. Facebook, Twitter). However, only a limited number of resources (12, $4 \%$ websites and $8 \%$ Web-based and mobile apps) allow for users to contribute. For earthquake resources (such as USGS "Did you feel it?", INGV website), the contribution made by users is usually limited to reporting of intensity of shaking felt during a seismic event. Furthermore, with the exception of some well-known examples (e.g. Shake Out, Get Ready), interventions and community events are rarely advertised via Web and mobile apps, suggesting a lack of the dynamic character that would favour citizen engagement.

Similarly, apps typically include a map interface of worldwide or country-wide extent showing the location of the most recent earthquakes and the listing of their characteristics (e.g. occurrence, intensity, depth of an earthquake). Some applications offer the opportunity to customise the 'alerts' service to receive only the notifications of earthquakes above a pre-defined magnitude or within a certain distance from the user. Others offer an overview of the extent of the affected areas (e.g. USGS Shakemaps overlay). However, no indication is given on the maps of the locations of community-led activities for earthquake and fire preparedness that may be occurring in the close proximity of the user. This is an intrinsic limitation of such technologies, typically directed at single end-users rather than at communities as a whole. As such, the current resources do not facilitate the formation of 
preparedness behaviour at the community level, nor do they increase the community-level sense of agency regarding preparedness.

\section{(d) Delivery of actionable and comprehensive information}

Websites usually distribute preparedness information to the public as a set of guidelines or 'do/don't' lists for earthquake and/or fire preparedness. Besides the web, channels of distribution include blog posts, tweets, newsletters, and social media. Guidelines often distinguish between actions to be performed before, during and after the event. These are supplemented by short descriptions of the characteristics of the targeted hazards and how they affect structural and non-structural features of buildings.

Fewer than half ( $44 \%$ ) of the reviewed websites provide actionable preparedness information, showing efforts from the primary providers in leading and facilitating preparedness in communities.

\subsection{Earthquake resources analysed in this study}

With regard to earthquake preparedness, the content of the 76 reviewed websites is detailed in Figs. 1, 2, 3 and Table 1. Figure 1 shows the frequency of recurrence of pre-event information distributed for earthquake preparedness.

Most common measures regarding what one can do before an earthquake include learning how to build an emergency kit and devising a family communication plan, as well as practicing the family earthquake drills and the 'drop, cover, and hold on' position. Out of the 76 websites delivering information for earthquake preparedness, $75 \%(n=57)$ provide instructions and, at times, templates for the creation of a family plan, $74 \%$ $(n=56)$ list instructions and key supplies for a complete earthquake kit, and $60 \%$ ( $n=46)$ advise users to be aware of the risks linked to being in a seismically active zone. Less than half of the websites $(45 \%-n=34)$ promote family drills and practicing the 'Drop, cover, and hold on' position; and even fewer $(32 \%-n=24)$ advise users to practice how to shut off utilities. Only $49 \%$ of the 76 websites $(n=37)$ encourage setting up a network of contacts, including close relatives and also more distant contacts. Even fewer websites $(22 \%-n=17)$ suggest getting involved in local activities.

Taking precautions against onerous repair costs is also given minimal priority, with only $13 \%$ of the websites $(n=10)$ instructing users on how to minimise financial risks (e.g. insurance, appropriate storage of valuable documents). Prominence is instead given to other precautionary measures that are frequently repeated in the websites and that are indicated as the most efficient ways to prevent damage from occurring. Non-structural measures are more common and include securing heavy appliances or moving them onto the floor when possible ( $57 \%$ of the websites $-n=43$ ), using anti-slip pads on small objects that may fall from shelves ( $32 \%-n=24)$, and applying latches to cupboards to prevent objects from falling and spillage of dangerous products $(39 \%-n=30)$. Structural adjustments include securing loose roof tiles, which could slide and hurt people trying to evacuate, as well as checking connections between walls, ceilings, and foundations (37 \%-n $n=28$ ). Some websites also suggest installing flexible piping systems to avoid gas leaks $(21 \%-n=16)$.

Regarding the actions that users should perform during an earthquake (Fig. 2), nearly all of the reviewed websites ( $95 \%-n=72$ ) suggest to perform the 'Drop, cover and hold on' position covering head and neck at the first sign of shaking, to avoid evacuating the building until the shaking has stopped ( $96 \%-n=73$ ), and to stay calm (96\%-n=73). The rules are stated as applying to everyone, including people in wheelchairs, with the 
Create a family plan

Have a family earthquake kit with listed key supplies

Be aware of the risks linked to being in a seismic active zone

Secure heavy appliances or move them on the floor when possible

Set up a network of contacts, including close relatives and more distant contacts

Have family drills and practice the 'Drop, cover, and hold on' position

Apply latches to cupboards to prevent objects from falling and spillage of dangerous products

Use anti-skip pads on small objects that may fall from shelves

Practice how to shut off utilities

Get involved in local preparedness activities

Install flexible piping systems to avoid gas leaks

Minimise financial risks (e.g., insurance, appropriate storage of valuable documents)

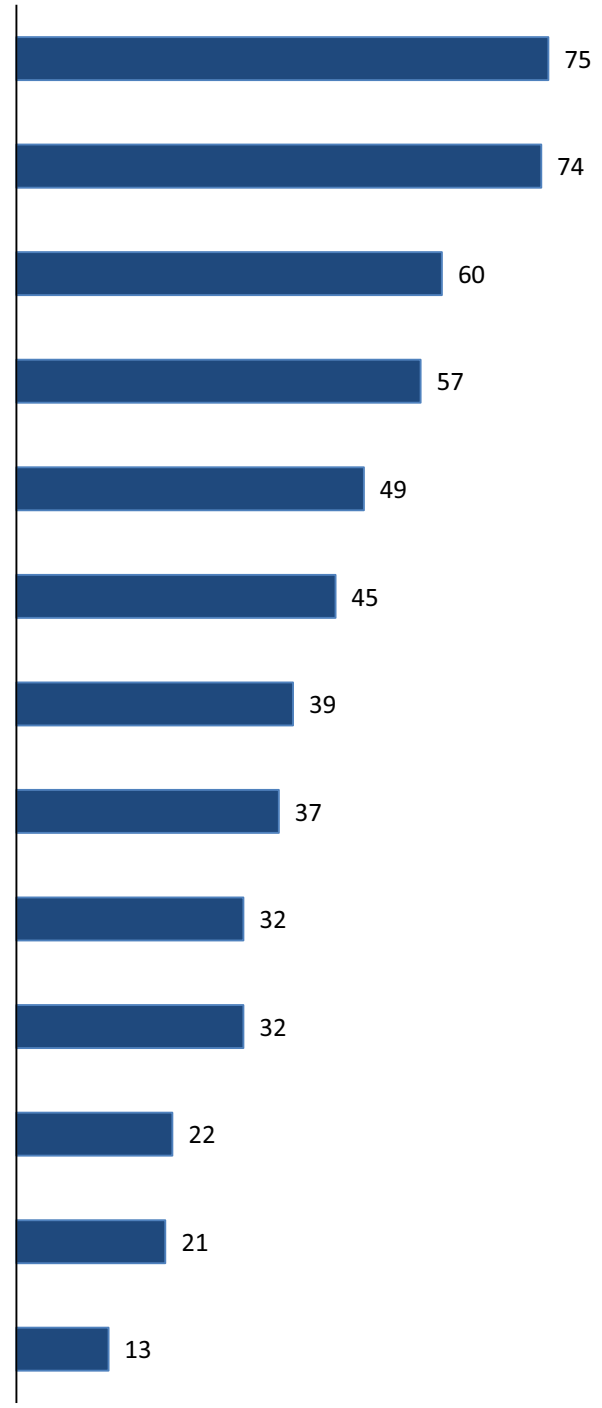

Fig. 1 List of recommendations on earthquake preparedness (\% of websites reviewed -76 in total)

exception of people in cars, who are advised to stop the car safely, and people lying in bed, who are advised to stay still and protect themselves with a pillow. Other precautions include staying away from windows and potential falling object $(79 \%-n=60)$, and avoiding using escalators $(66 \%-n=50)$ when leaving a building. Once evacuation is possible, it is important to exit promptly and move away from buildings, paying attention to potential causes of injury and damage. The most common post-earthquake actions are summarised in Fig. 3.

In the post-earthquake phase, users should check their surroundings $(66 \%-n=50)$ for broken glass, toxic spillages, and fallen walls, and be aware of the possibility of aftershocks and secondary effects $(58 \%-n=44)$. Users are also advised to stay 


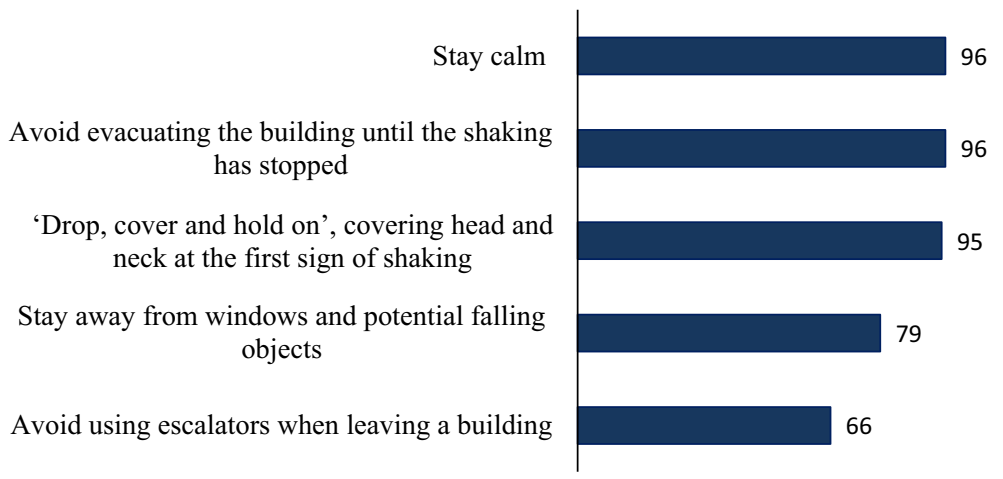

Fig. 2 List of recommendations on what to do during an earthquake (\% of websites reviewed-76 in total)

Once evacuation is possible, exit promptly and move away from buildings

Stay connected to media channels

Be aware of the possibility of aftershocks and secondary effects

Start clean up operations steadily but with caution

Check for personal and family members' injuries

Check on neighbours and other members of the community, help them if able to do so

Check for house damage, which includes inspecting utilities

Inspect structural soundness

Re-enter the house only when told it is safe to do so

Deal with fire if easily extinguishable, as soon as ground shaking has halted, or evacuate

Arrange for repairs/claims

In cases where buildings may be unsound, find the nearest shelter

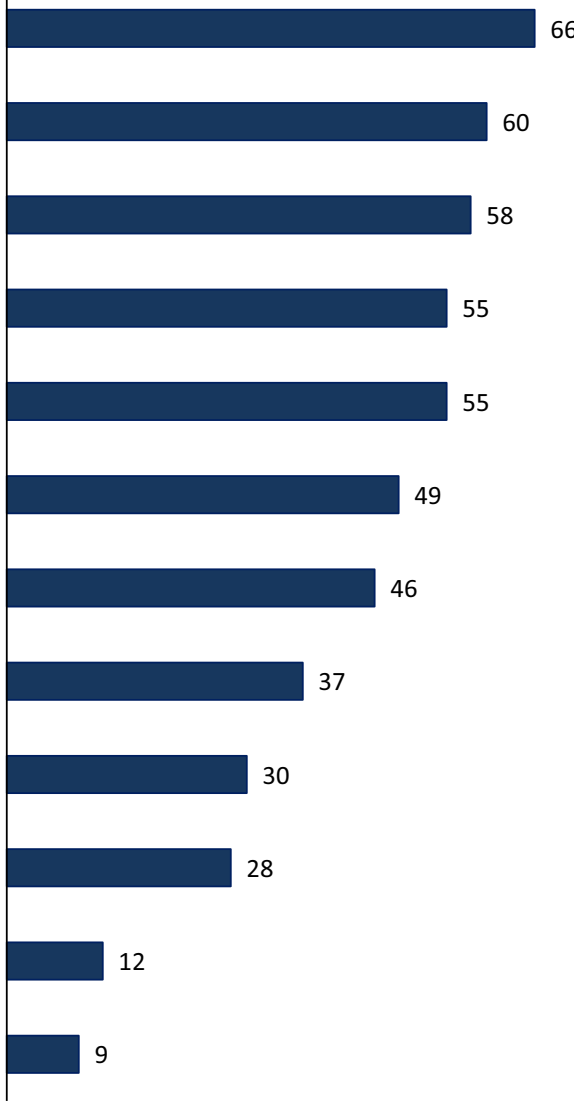

Fig. 3 List of recommendations on post-earthquake actions (\% of websites reviewed-76 in total)

connected to media channels $(60 \%-n=46)$. The reconnaissance of injuries and damage should follow a precise order. First, personal and family members' injuries (55\%$n=42)$, then house damage, which includes inspecting utilities $(46 \%-n=35)$, 
Table 1 Earthquake preparedness information (\% of websites reviewed-76 in total) delivered and corresponding preparedness functional category

Functional $\%$

category

\section{Before an earthquake}

Create a family plan

Have a family earthquake kit with listed key supplies

Be aware of the risks linked to being in a seismically active zone

Secure heavy appliances or move them onto the floor when possible

Set up a network of contacts, including close relatives and more distant contacts

Have family drills and practice the 'Drop, cover, and hold on' position

Apply latches to cupboards to prevent objects from falling and spillage of dangerous products

Perform structural adjustments including securing loose roof tiles, which could slide and hurt people trying to evacuate, as well as checking connections between walls, ceilings, and foundations

Practice how to shut off utilities

Use anti-slip pads on small objects that may fall from shelves

Get involved in local preparedness activities

Install flexible piping systems to avoid gas leaks

Minimise financial risks (e.g. insurance, appropriate storage of valuable documents)

During an earthquake

Avoid evacuating the building until the shaking has stopped

Stay calm

'Drop, cover and hold on' position covering head and neck at the first sign of shaking S

Stay away from windows and potential falling objects

Avoid using escalators when leaving a building

After an earthquake

Once evacuation is possible, exit promptly and move away from buildings, paying $\mathrm{S}$ attention to broken glass, toxic spillages, and fallen walls, etc.

Stay connected to media channels

C 60

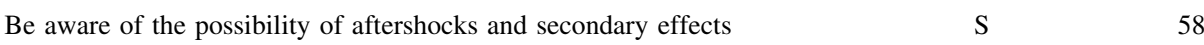

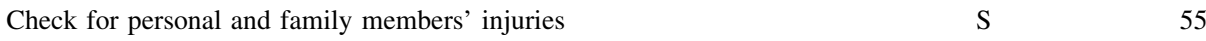

Start clean-up operations steadily but with caution $\quad S$

Check on neighbours and other members of the community; help them if able to do $\mathrm{C}$

Check for house damage, which includes inspecting utilities

Inspecting structural soundness

Re-enter the house only when told it is safe to do so

In case of fire, deal with it only if it can be extinguished easily as soon as ground $S$ shaking has halted, or evacuate immediately if the fire is large

Arrange for repairs/claims

In cases where buildings may be unsound, find the nearest shelter

Functional category legend: $C$ community, $P$ planning, $S$ survival, $S M$ structural mitigation) 
inspecting structural soundness (37\%-n $=28$ ) and arranging for repairs/claims (12\%$n=9$ ), and lastly checking on neighbours and other members of the community, helping them if able to do so (49\%-n=37). Clean-up operations should start steadily but should always be performed with caution $(55 \%-n=42)$. In cases where buildings have sustained heavy damage and may be structurally unsound, families are instructed to locate the nearest shelter but to leave a trail of their movements, so that they can be told if/when it is safe to return home $(9 \%-n=17)$. Users are strongly advised to re-enter the house only when safe (30\%-n=23). Details of specifically what makes a building safe, or when it might be safe to re-enter a building after an event, are however not given.

Less than a third of the analysed websites $(28 \%-n=21)$ mention fire as one of the likely consequences of an earthquake, stating that fire should be dealt with only if it can be extinguished easily as soon as ground shaking has halted, or to evacuate immediately if the fire is large.

Table 1 summarises the actions suggested by the websites, categorising those to be done before, during and after an earthquake in terms of the following categories of preparedness: $\mathrm{P}$-planning, S-survival, SM-structural mitigation, and $\mathrm{C}$-community. The table highlights that preparedness information related to survival and planning dominate where structural mitigation and community building are less prevalent, especially with regard to actions to be undertaken during and after an earthquake, when the key objective is to safeguard life and protect against further injuries.

Actions connected to structural mitigation and community preparedness are seldom listed. Recommendations linked to community preparedness only suggest that people remain connected to key information channels and to the community in general. No mention is given to activities that would encourage the creation of community sense of agency.

\subsection{Fire resources analysed in this study}

Turning from earthquakes to home fires, precautionary measures vary according to the website under consideration. The content of the nine websites reviewed is detailed in Figs. 4, 5 and Table 2. Figure 4 lists the most frequent pre-event precautionary measures for home fire preparedness.

The pre-event recommendations include having a fire escape plan $(78 \%-n=7)$ and a fire extinguisher $(67 \%-n=6)$. Some websites stress the importance of being environmentally aware, and being familiar with all possible escape routes regarding each room, with some $(33 \%-n=3)$ suggesting identifying at least two escape routes from every room. Smoke alarms are also regarded as important; however, only the $33 \%(n=3)$ of the websites remark on the need to have one for each room and to test them on a monthly basis. Only one website $(11 \%)$ provides information on when one should replace the smoke alarm (i.e. every 10 years), whilst another two websites (22\%) encourage changing the batteries of the smoke alarm at least twice a year. Only $22 \%$ of the reviewed websites $(n=2)$ suggest the purchase of collapsible fire escape ladders. Other measures include sleeping with closed doors to avoid fire propagation from one room into another, not smoking in bed, not placing any objects near burners, heaters or stoves and unplugging electrical appliances when away from home for significant duration. For extra precaution, users are also advised to dispose of any electronics with frayed wires, to make sure that cigarettes are completely extinguished, to avoid leaving cooking food unattended, to vacuum and dust smoke alarms weekly and to keep matches and lighters safely out of reach 
Have a fire escape plan

Have a fire extinguisher

Have a smoke alarm for each room and test it on a monthly basis

Be familiar with all possible escape routes of each room

Purchase of collapsible fire escape ladders

Change the batteries of the smoke alarm at least twice a year

Change the fire alarm every 10 years
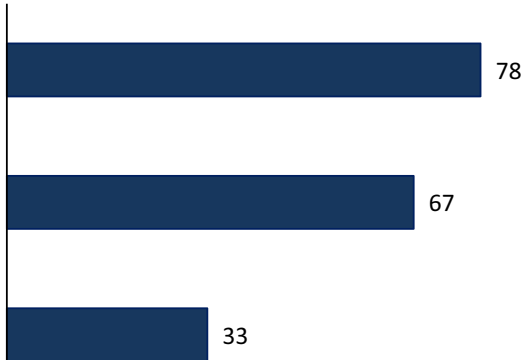

33 33

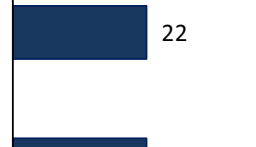

22

11

Fig. 4 List of recommendations for home fire preparedness (\% of websites reviewed-9 in total)

During the fire, 'get low and go'; crawl under the smoke and leave the building, unless the fire can be easily extinguished

If trapped in fire, limit smoke inhalation; go to the window/balcony; signalling position to fire fighters with a colourful cloth when possible

Be cautious before opening doors for escaping and close doors when leaving the premises so as to contain fire

Do not use elevators

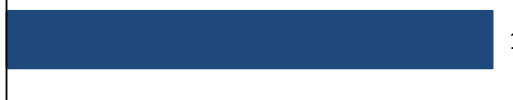

'Stop, Drop, and Roll' in case clothes catch fire
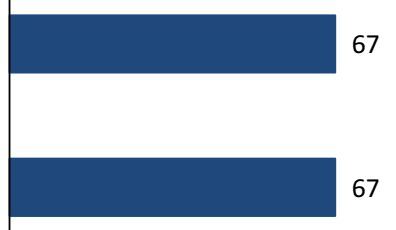

Fig. 5 List of recommendations for what to do during a fire (\% of websites reviewed -9 in total) 
Table 2 Home fire preparedness information and corresponding preparedness functional category (\% of websites reviewed-9 in total)

\section{Before a fire}

Have a fire escape plan

Have a fire extinguisher

$\mathrm{P}$

$\mathrm{P}$

Be familiar with all possible escape routes from each room

Have a smoke alarm for each room and test it on a monthly basis

Change the batteries of the smoke alarm at least twice a year

Purchase collapsible fire escape ladders

When to change the fire alarm (i.e. 10 years)

During a fire

During the fire, all websites recommend 'get low and go', crawl under the smoke S and leave the building, unless the fire can be easily extinguished

Be cautious before opening doors for escaping (i.e. feeling the door knob, opening $S$ the door slowly), and close doors when leaving the premises so as to contain fire

If trapped in fire, limit smoke inhalation, by covering cracks in the door, by $\mathrm{S}$ breathing through a wet cloth, or by going to the balcony or standing before a window so as to be easily located, signalling position to fire fighters with a colourful cloth when possible

Do not use elevators

'Stop, Drop, and Roll' in case clothes catch fire

After a fire

Once out, go to the assembly point and call for help

Functional category legend: $P$ planning, $S$ survival)

of children. With regards to fixed improvement to the house, one website suggests considering installing an automatic fire sprinkler system.

During the fire (Fig. 5), all websites recommend 'get low and go', to crawl under the smoke and leave the building, unless the fire can be easily extinguished.

Once out of the building, the standard procedure requires one to go to the assembly point and to call for help ( $88 \%-n=8)$. Six websites $(67 \%)$ suggest that one is cautious before opening doors for escaping (i.e. feeling the door knob, opening the door slowly) and that one closes doors when leaving the premises so as to contain fire. The use of elevators is discouraged in the websites surveyed (56\%-n=5).

The 'Stop, Drop, and Roll' routine is recommend by three websites (33\%) in case clothes catch fire. If trapped in fire, most recommended safety measures include limiting smoke inhalation by covering cracks in the door, breathing through a wet cloth, or going to the balcony or standing by a window so as to be easily located $(67 \%-n=6)$ and signalling one's position to fire fighters with a colourful cloth when possible. The following table summarises the actions suggested by the websites, categorising them into what must be done before, during and after a fire and linking them to the relevant functional category of preparedness. Even more evident than in the summary of the earthquake preparedness recommendations is the almost exclusive orientation of fire preparedness 
information towards survival and planning, with community preparedness actions being completely overlooked.

Overall, as far as the websites are concerned, not all of the resources provide the same level of detail in the description of what a user must do before, during, and after an earthquake and/or home fire to better anticipate, cope with and recover from it. Information content varies greatly, thus making it possible for users consulting more than one resource to be confused as to which preparedness measures should be prioritised and for what reason. Trust in the provider would be pivotal in which instructions were followed.

With regard to mobile applications, it was found that their current design as "on-thego" portals of live feeds may not be the best way for dissemination of preparedness information, as it entails no supervision. Only the applications whose development and distribution has been supervised by authorities in the field of disaster risk reduction and response (e.g. American Red Cross and FEMA) include features that increase interactivity with the user and real-time usefulness. In contrast to these, applications developed and distributed by "non-authorities" lack features for the distribution of preparedness information.

For instance, the American Red Cross Earthquake app not only notifies user when an earthquake occurs close to their location, but also allows users to transmit messages to let others know they are safe. The customizable "I'm safe" alert can be sent via Facebook, Twitter, email or SMS text message. The preparedness component of the application consists of step-by-step instructions on what to do before and after an earthquake, which remains available for consultation offline if data connectivity is lost. The application also offers the opportunity to find the closest shelter in case of need. Finally, should the user become trapped, the application Toolkit includes a strobe light, a flashlight and an audible alert. Similarly, the FEMA app contains preparedness information for different types of disasters, an interactive checklist for emergency kits, a section to plan emergency meeting locations, information on how to stay safe and recover after a disaster, a map with FEMA Disaster Recovery Centre locations and shelters, general ways the public can get involved before and after a disaster, and the FEMA blog. There appear to be no real-time apps devoted specifically to home fire events.

\section{(e) Cultural relevance to specific context/group}

The websites tend to target their preparedness information at families and so information is mostly directed to parents or caregivers. For earthquakes very few of the analysed websites provide customised information for particularly vulnerable groups or include group-specific guidelines in their more general information (8\% for seniors, $9 \%$ people with disabilities, $9 \%$ children; $10 \%$ for pet owners, $1 \%$ for apartment and mobile homes managers). None of the websites investigated for fire provided customised information for vulnerable building occupants.

(f) Behaviour Change Techniques: Reminders, Positive Reinforcement, Rewards and (g) Evaluation

Even though the preparedness information delivered by the websites state clearly that many preparedness activities (e.g. drills, checking the emergency kit, checking the battery of smoke alarms) need to be repeated over time or at regular time intervals to ensure their efficacy, none of the resources analysed has implemented any means to remind users about their need to remain prepared over time nor do any monitor progress towards enhanced preparedness. The lack of these dynamic interactive features reduces the chances of users returning to the websites or applications for more continuous and sustained learning. 
As far as positive reinforcement and rewards are concerned, of all the resources evaluated, only the Web game 'Beat the Quake' (publicised by the Earthquake Country Alliance organisation and produced by the Illusion Factory) and the Ready.gov game 'Disaster Master' provide visual campaigns incorporating a reward system (i.e. points) or penalty (i.e. end of game) that encourage the user to seek a better score, thus facilitating learning. The 'Beat the Quake' Web game targets the general public. The game is structured to promote earthquake safety and awareness and provides some preliminary training about the potential risks and sources of harm associated with earthquakes. After a brief online training, the user is invited to "Beat the Quake" by securing as many objects and furniture in the most appropriate way before an earthquake-type shaking occurs in the game. The Web game essentially tests the safety knowledge of the user, with regards to what to do to prevent injury and damage inside a house. After the earthquake occurs, the application returns a final score that the user can share with others to invite them to play and, hence, to be more prepared about safety in earthquakes. In September 2015, an updated version of the video game was developed to include fire safety elements, thus making the game a tool for learning and practicing multi-hazard preparedness. Links to both the Earthquake Alliance and to the Shake Out websites are provided, offering opportunities to learn more about preparedness and get connected with the local communities.

The Ready.gov web game 'Disaster Master' targets children. It provides detailed information concerning what children should know in case of disasters, including earthquakes and home fires. The game consists of helping the game characters in making correct decisions to earn points and unlock higher game levels. Incorrect choices end the game, so the final purpose is for children to repeat the game until they are able to survive all seven levels, each of which is associated with a disaster scenario. As a reward for the completion of all seven levels, children are granted the title of 'Disaster Master' and can finally print out chapters of a personalised graphic novel where they are the main characters.

Both 'Beat the Quake' and 'Disaster Master' use graphics and rewards to help user remember the preparedness information in the narrative. Nonetheless, their effectiveness is limited to the users who are already motivated to learn about preparedness and look for information on the Web, or that are being taught about preparedness in their specific social context by means of these Web resources

\section{Conclusions and recommendations}

Websites and apps can be used to distribute important preparedness information to the people who can be reached by such technologies. These novel means of digital engagement have the potential to encourage both individuals and communities to be more proactively involved in fire and earthquake hazard preparedness. However, this potential has not been fully investigated or exploited, and more importantly there is a need to understand how these tools are used and what their long-term impact is on preparedness activities.

The review in this paper has revealed that the currently available Web and mobile resources addressing home fire and earthquake preparedness contain a number of shortcomings; these need to be addressed to improve the efficacy of ICT for multi-hazard earthquake and fire preparedness. The following evaluation matrix (Table 3) summarises the finding of the review in relation to the nine main criteria investigated. 
Table 3 Evaluation matrix of the findings of the review

\begin{tabular}{|c|c|c|c|c|}
\hline \multirow[t]{2}{*}{ Criteria } & \multicolumn{2}{|l|}{ Websites } & \multicolumn{2}{|c|}{ Mobile applications } \\
\hline & $(\%)$ & Rating & $(\%)$ & Rating \\
\hline $\begin{array}{l}\text { Delivery of multi-hazard } \\
\text { earthquake-fire preparedness } \\
\text { information }\end{array}$ & $25 \%$ & $\begin{array}{l}\text { Needs } \\
\text { improvement }\end{array}$ & $0 \%$ & $\begin{array}{l}\text { Needs } \\
\text { improvement }\end{array}$ \\
\hline $\begin{array}{l}\text { Competency of information } \\
\text { provider for actionable } \\
\text { information }\end{array}$ & $80 \%$ & Very good & $\begin{array}{l}\text { American Red } \\
\text { Cross and } \\
\text { FEMA apps } \\
(1 \%)\end{array}$ & $\begin{array}{l}\text { Needs } \\
\text { improvement }\end{array}$ \\
\hline $\begin{array}{l}\text { Level of interaction between } \\
\text { host/moderator and the general } \\
\text { public and between the users }\end{array}$ & $4 \%$ & $\begin{array}{l}\text { Needs } \\
\text { improvement }\end{array}$ & $8 \%$ & $\begin{array}{l}\text { Needs } \\
\text { improvement }\end{array}$ \\
\hline $\begin{array}{l}\text { Delivery of actionable and } \\
\text { comprehensive information }\end{array}$ & $44 \%$ & $\begin{array}{l}\text { Needs } \\
\text { improvement }\end{array}$ & $\begin{array}{l}\text { American Red } \\
\text { Cross and } \\
\text { FEMA apps } \\
(1 \%)\end{array}$ & $\begin{array}{l}\text { Needs } \\
\text { improvement }\end{array}$ \\
\hline $\begin{array}{l}\text { Cultural relevance to specific } \\
\text { context/group }\end{array}$ & & $\begin{array}{l}\text { Needs } \\
\text { improvement }\end{array}$ & $0 \%$ & $\begin{array}{l}\text { Needs } \\
\text { improvement }\end{array}$ \\
\hline For seniors; & $8 \%$ & & & \\
\hline People with disabilities; & $9 \%$ & & & \\
\hline Children; & $9 \%$ & & & \\
\hline For pet owners; & $10 \%$ & & & \\
\hline $\begin{array}{l}\text { For apartment and mobile } \\
\text { homes managers }\end{array}$ & $1 \%$ & & & \\
\hline Use of reminders & $0 \%$ & $\begin{array}{l}\text { Needs } \\
\text { improvement }\end{array}$ & $0 \%$ & $\begin{array}{l}\text { Needs } \\
\text { improvement }\end{array}$ \\
\hline $\begin{array}{l}\text { Use of positive reinforcements } \\
\text { and rewarding systems and }\end{array}$ & $\begin{array}{l}\text { "Beat the } \\
\text { quake" } \\
\text { "Disaster } \\
\text { Masters" } \\
(2 \%)\end{array}$ & $\begin{array}{l}\text { Needs } \\
\text { improvement }\end{array}$ & $0 \%$ & $\begin{array}{l}\text { Needs } \\
\text { improvement }\end{array}$ \\
\hline Monitoring of progress & $0 \%$ & $\begin{array}{l}\text { Needs } \\
\text { improvement }\end{array}$ & $0 \%$ & $\begin{array}{l}\text { Needs } \\
\text { improvement }\end{array}$ \\
\hline
\end{tabular}

Rating legend: Above $75 \%$, Very Good, 75-50\%-Good, Below $50 \%$-Needs improvement

Firstly, with notable exceptions, the lack of web- and mobile-based resources tailored to deliver information on multi-hazard preparedness points to the need for more research on how to approach preparedness from a holistic, multi-hazard perspective. Preparedness information is mainly delivered by government, research, and emergency response organizations with relevant knowledge in the field of preparedness. This could encourage the creation of a system of trust between authorities and the community, especially if such electronic offering are provided or customised at local level and advertised by means of community-based activities. Nonetheless, the general level of interaction between websites host/moderator and the general public is limited to social media interactions. This hinders the establishment of two-way communication between information providers and users, and therefore impedes the development and perpetuation of a system of trust. Community engagement and empowerment are also obstructed by this lack of two-way 
communication. Furthermore, this misses an interesting opportunity for relevant authorities to obtain real-time information on relevant risks and robust information within their particular jurisdictions.

In addition, the information distributed by means of websites and Web-based application is largely directed to families, caregivers, or individual users. The paper has highlighted a few examples of applications targeting children, but little or no regard is given to the specific needs of other vulnerable groups. Efforts should be made to reach all vulnerable groups-for which preparedness is arguably of even greater importance-with tailored preparedness measures. Preparedness information should be delivered based on the specific needs of the user, possibly with a screening process based on age, language and physical ability of the user at the moment of the application download, thus taking into account context-specific circumstances.

With regard to mobile applications, it was found that although some of the applications (i.e. American Red Cross) have been designed and targeted specifically to deliver preparedness information, the vast majority remain only a hub of disaster data, which does not stimulate the creation of new proactive behaviours towards preparedness nor preparedness habit formation.

However, several features could be included in the current standard design of such applications to increase their interactivity with the user. In particular, the current technology does not incorporate behaviour change techniques that have proven successful in supporting public investment in the message delivered in the health field. For instance, the use of reminders for preparedness behaviours that need to be repeated over time would be likely to increase the effectiveness of the applications. Furthermore, earthquake and home fire quizzes (e.g. do you remember when you last checked your fire alarm? How many of your essential supplies do you think are out-of-date?), which could pop up on the mobile of the user to test their preparedness, could be easily integrated into the design of future applications. As some of the recommendations for fire and earthquake preparedness only need to be performed once, it can be concluded that reminders per se will have a limited impact on behaviour change. Nonetheless, rewards could be used in association with reminders to stimulate the interest of the user towards a period reassessment of their preparedness skills. In addition, they could also be used to increase the perception of the need for proactive preparedness behaviour, so as to ensure that the importance of multihazard earthquake-fire preparedness is not downplayed in importance when compared with more frequent perils. In addition to this, information on the use of the application should be monitored over time so that users could review their personal preparedness scores and collect rewards.

Lastly, even though mapping tools are already embedded in the great majority of the applications, these currently lack functionality to provide supplementary information about the proximity of community-led, preparedness-orientated organisations and activities. Introducing tools to advertise and remind the user about community preparedness events could be a suitable way to re-project the individual into the community setting. This would also be likely to boost social cohesion with knock on benefits for preparedness and disaster response activities.

Acknowledgments This work was funded by the Engineering and Physical Sciences Research Council (Grant Ref. EP/K022377/1).

Open Access This article is distributed under the terms of the Creative Commons Attribution 4.0 International License (http://creativecommons.org/licenses/by/4.0/), which permits unrestricted use, distribution, 
and reproduction in any medium, provided you give appropriate credit to the original author(s) and the source, provide a link to the Creative Commons license, and indicate if changes were made.

\section{References}

American Red Cross (2010) Social media in disasters and emergencies. 5 Aug 2010

Bailey JV, Webster R, Hunter R, Freemantle N, Rait G, Michie S, Estcourt C (2015a) The Men's Safer Sex (MenSS) trial: protocol for a pilot randomised controlled trial of an interactive digital intervention to increase condom use in men. BMJ Open 5(2):e007552

Bailey JV, Webster R, Hunter R, Freemantle N, Rait G, Michie S, Estcourt C (2015b) The Men's Safer Sex (MenSS) trial: protocol for a pilot randomised controlled trial of an interactive digital intervention to increase condom use in men. BMJ Open 5(2):e007552

Ballantyne M, Paton D, Johnston D, Kozuch M, Daly M (2000) Information on volcanic and earthquake hazards: the impact on awareness and preparation (Institute of Geological \& Nuclear Sciences Limited Science Report 2000/2). GNS Science, Wellington

Bauer M, Durant J, Evans G (1994) European public perceptions of science. Int J Public Opin Res 6(2):163-186

Brendryen H, Drozd F, Kraft P (2008) A digital smoking cessation program delivered through internet and cell phone without nicotine replacement (happy ending): randomized controlled trial. J Med Internet Res 10(5):e51

Briones RL, Kuch B, Fisher Liu B, Jin Y (2011) Keeping up with the digital age: How the American Red Cross uses social media to build relationships. Public Relat Rev 37(1):37-43

Coyle D, Meier P (2009) New technologies in emergencies and conflicts: the role of information and social networks. UN Foundation-Vodafone Foundation Partnership, Washington

Devine-Wright H, Devine-Wright P (2004) From demand side management to demand side participation: towards an environmental psychology of sustainable electricity system evolution. J Appl Psychol 6(3-4):167-177

Duval TS, Mulilis JP (1999) A person-relative-to-event (PrE) approach to negative threat appeals and earthquake preparedness: a field study. J Appl Soc Psychol 29(3):495-516

Eden S (1996) Public participation in environmental policy: considering scientific, counter-scientific and non-scientific contributions. Public Underst Sci 5:183-203

Eiser RJ, Bostrom A, Burton I, Johnston DM, McClure J, Paton D, Van der Pligt J, White MP (2012) Int J Disaster Risk Reduct 1:5-16

Evans G, Durant J (1995) The relationship between knowledge and attitudes in the public understanding science in Britain. Public Underst Sci 4(1):57-74

Free C, Phillips G, Galli L, Watson L, Felix L, Edwards P, Haines A (2013) The effectiveness of mobilehealth technology-based health behaviour change or disease management interventions for health care consumers: a systematic review. PLoS Med 10(1):e1001362

Giroux J, Roth F, Herzog M (2013) Using ICT \& social media in disasters: opportunities \& risks for government-background document. Center for Security Studies (CSS), ETH Zurich

Haisley E, Volpp KG, Pellathy T, Loewenstein G (2012) The impact of alternative incentive schemes on completion of health risk assessments. Am J Health Promot 26(3):185-188

Hunter R, Tully MA, Davis M, Kee F (2013) Physical activity loyalty cards for behavior change: a quasiexperimental study. Am J Prevent Med 45(1):56-63

International Telecommunications Union (ITU) (2014) Measuring the information society report 2014. ITU, Geneva. Accessed 1 April 2015. http://www.itu.int/en/ITU-D/Statistics/Documents/publications/ mis2014/MIS2014_without_Annex_4.pdf

Jaeger PT, Subramaniam M, Jones CB, Bertot JC (2011) Diversity and LIS education: inclusion and the age of the information. J Educ Library Inf 52:166-183

Joffe H, Rossetto T, Solberg C, O'Connor C (2013) Social representations of earthquakes: a study of people living in three highly seismic areas. Earthq Spectra 29(2):367-397

Johnson SM (1998) The internet changes everything: revolutionizing public participation and access to government information through the internet. Adm Law Rev 50(2):277-337. American Bar Association Stable. http://www.jstor.org/stable/40709905

Johnston D, Bebbington MS, Lai CD, Houghton BF, Paton D (1999) Volcanic hazard perceptions: comparative shifts in knowledge and risk. Disaster Prev Manage 8:118-126 
Johnston D, Becker J, McClure J, Paton D, McBride S, Wright K (2013) Community understanding of, and preparedness for, earthquake and tsunami risk in Wellington, New Zealand. In: Joffe H, Rossetto T, Adams J (eds) Cities at risk, vol 33. Springer, Netherlands, pp 131-148

Karanci AN, Aksit B, Dirik G (2005) Impact of a community disaster awareness training program in Turkey: does it influence hazard-related cognitions and preparedness behaviors. Soc Behav Personal Int J 33(3):243-258

Khadjesari Z, Murray E, Hewitt C, Hartley S, Godfrey C (2011) Can stand-alone computer-based interventions reduce alcohol consumption? A systematic review. Addiction 106(2):267-282

Kimmel SE, Troxel AB, Loewenstein G, Brensinger CM, Jaskwiak J, Doshi JA, Laskin M, Volpp K (2012) Randomized trial of lottery-based incentives to improve warfarin adherence. Am Heart J 164(2):268-274

Krishna S, Boren SA, Balas EA (2009) Healthcare via cell phones: a systematic review. Telemed J E Health 15:231-240

Lally P, Van Jaarsveld CHM, Potts HW, Wardle J (2010) How habits are formed: modelling habit formation in the real world. Eur J Soc Psychol 40:998-1009

Lindell MK, Perry RW (2000) Household adjustment to earthquake hazard a review of research. Environ Behav 32(4):461-501

Lindell MK, Whitney DJ (2000) Correlates of household seismic hazard adjustment adoption. Risk Anal 20(1):13-26

Lindell MK, Arlikatti S, Prater CS (2009) Why people do what they do to protect against earthquake risk: perceptions of hazard adjustment attributes. Risk Anal 29(8):1072-1088

Lindsay BR (2011) Social media and disasters: current uses, future options, and policy considerations. CRS report for congress, 7-5700, R41987. Accessed 1 Apr 2015. http://www.fas.org/sgp/crs/homesec/ R41987.pdf

McGowan, F., Sauter, R. (2005). Public opinion on energy research: a desk study for the research councils. Sussex Energy Group, SPRU, University of Sussex

McKenzie-Mohr D (2000) Promoting sustainable behavior: an introduction to community-based social marketing. J Soc Issues 56(3):543-554

Meacham BJ (1999) Integrating human factors issues into engineered fire safety design. Fire Mater 23(1):273-279

Michie S, Johnston M, Francis J, Hardeman W, Eccles M (2008) From theory to intervention: mapping theoretically derived behavioural determinants to behaviour change techniques. Appl Psychol 57(4):660-680

Milkman KL, Beshears J, Choi JJ, Laibson D, Madrian BC (2011) Using implementation intentions prompts to enhance influenza vaccination rates. Proc Natl Acad Sci (PNAS) 108(26):10415-10420

Mulilis JP, Lippa R (1990) Behavioral change in earthquake preparedness due to negative threat appeals: a test of protection motivation theory. J Appl Soc Psychol 20(8):619-638

Norris FH, Stevens SP, Pfefferbaum B, Wyche KF, Pfefferbaum RL (2008) Community resilience as a metaphor, theory, set of capacities, and strategy for disaster readiness. Am J Commun Psychol 41(1):127-150

Palen L, Hiltz SR, Liu SB (2007) Online forums supporting grassroots participation in emergency preparedness and response. Commun ACM 50(3):54-58

Paton D (2006) Disaster resilience: building capacity to co-exist with natural hazards and their consequences. In: Paton D, Johnston D (eds) Disaster resilience: an integrated approach. Charles C. Thomas, Springfield, Ill, pp 3-10

Paton D (2007) Preparing for natural hazards: the role of community trust. Disaster Prevent Manag Int J 16(3):370-379

Paton D, Johnston D (2001) Disasters and communities: vulnerability, resilience and preparedness. Disaster Prevent Manag 10(4):270-277

Paton D, Johnston D (2015) The Christchurch earthquake: integrating perspectives from diverse disciplines. Int J Disaster Risk Reduct 14:1-5

Paton D, Smith L, Johnston D (2005) When good intentions turn bad: promoting natural hazard preparedness. Emerg Manag Aust 20(1):25-30

Paton D, Smith L, Daly M, Johnston D (2008) Risk perception and volcanic hazard mitigation: individual and social perspectives. J Volcanol Geotherm Res 172(3):179-188

Paton D, Bajek R, Okada N, McIvor D (2010a) Predicting community earthquake preparedness: a crosscultural comparison of Japan and New Zealand. Nat Hazards 54:765-781

Paton D, Sagala S, Okada N, Jang L, Burgelt PT, Gregg CE (2010b) Making sense of natural hazard mitigation: personal, social and cultural influences. Environ Hazards 9(2):183-196 
Paton D, Anderson E, Becker J, Petersen J (2015) Developing a comprehensive model of hazard preparedness: lessons from the Christchurch earthquake. Int J Disaster Risk Reduct 14:37-45

Reddick C (2011) Information technology and emergency management: preparedness and planning in US states. Disasters 35(1):45-61

Rogers Y, Sharp H, Preece J (2011) Interaction design: beyond human-computer interaction. J. Wiley \& Sons, Chichester, West Sussex

Russell LA, Goltz JD, Bourque JD (1995) Preparedness and hazard mitigation actions before and after two earthquakes. Environ Behav 27:744-770

Rüstemli A, Karanci AN (1999) Correlates of earthquake cognitions and preparedness behavior in a victimized population. J Soc Psychol 139(1):91-101

Shklovski I, Burke M, Kiesler S, Kraut R (2010) Technology adoption and use in the aftermath of Hurricane Katrina in New Orleans. Am Behav Sci 53(8):1228-1246

Smith K (1993) Environmental hazards: assessing risk and reducing disaster. Routledge, London

Solberg C, Rossetto T, Joffe H (2010) The social psychology of seismic hazard adjustment: re-evaluating the international literature. Nat Hazards Earth Syst Sci 10(1):1663-1677

Spittal MJ, Walkey FH, McClure J, Siegert RJ, Ballantyne KE (2006) The Earthquake Readiness Scale: the development of a valid and reliable unifactorial measure. Nat Hazards 39(1):15-29

Sturgis PJ, Allum NC (2001) Gender differences in scientific knowledge and attitudes toward science: reply to Hayes and Tariq. Public Underst Sci 10(4):427-430

Tierney KJ, Lindell MK, Perry RW (2001) Facing the unexpected: disaster preparedness and response in the United States. Joseph Henry Press, Washington

Turner RH, Nigg JM, Paz DH (1986) Waiting for disaster: Earthquake watch in California. University of California Press, California

United Nations Asian and Pacific Training Centre for Information and Communication Technology for Development (UN-APCICT/ESCAP) (2009) ICT for disaster risk reduction-issue 2. Accessed $3 \mathrm{Apr}$ 2015. http://www.preventionweb.net/files/14338_14338ICTDCaseStudy21.pdf

United Nations International Strategy for Disaster Reduction (2009) UNISDR terminology on disaster risk reduction. United Nations International Strategy for Disaster Reduction (UNISDR), Geneva. http:// www.unisdr.org/eng/terminology/terminology-2009-eng.html

Wayne N, Ritvo P (2014) Smartphone-enabled health coach intervention for people with diabetes from a modest socioeconomic strata community: single-arm longitudinal feasibility study. J Med Internet Res 16(6):e149

Webb T, Joseph J, Yardley L, Michie S (2010) Using the internet to promote health behavior change: a systematic review and meta-analysis of the impact of theoretical basis, use of behavior change techniques, and mode of delivery on efficacy. J Med Internet Res 12(1):e4 